\title{
Changes in the clinical presentation and outcomes of patients treated for severe malaria in a referral French university intensive care unit from 2004 to 2017
}

\author{
Jordane Lebut ${ }^{1,4}$, Bruno Mourvillier ${ }^{1,5}$, Nicolas Argy ${ }^{2}$, Claire Dupuis ${ }^{1,3}$, Camille Vinclair ${ }^{1}$, Aguila Radjou', \\ Etienne de Montmollin 1,3, Fabrice Sinnah¹, Juliette Patrier ${ }^{1}$, Clément Le Bihan ${ }^{1,3}$, Eric Magalahes ${ }^{1}$, \\ Roland Smonig' ${ }^{1}$, Eric Kendjo ${ }^{5}$, Marc Thellier ${ }^{5}$, Stéphane Ruckly ${ }^{6}$, Lila Bouadma ${ }^{1,3}$, Michel Wolff,3, \\ Romain Sonneville ${ }^{1,3}$, Sandrine Houzé ${ }^{2}$ and Jean-François Timsit ${ }^{1,3,6^{*}}$ (1)
}

\begin{abstract}
Background: In France, the incidence of severe imported malaria cases increased since early 2000. Artesunate was available (temporarily use authorization) since mid-2011 in France and commonly used for severe malaria since early 2013. Thus, the study objectives were to describe the patients with severe imported malaria admitted in intensive care unit (ICU) and assess the changes in clinical presentation and outcomes before and after this date.

Methods: Retrospective observational single-center study in the infectious diseases ICU of a referral university hospital, conducted on patients admitted for severe imported malaria from 2004 to 2017. Demographic variables, severity scores, WHO's severity criteria on admission, treatment, and ICU and hospital lengths of stay were collected. Patients' characteristics and outcomes were compared between both periods. A poor outcome was defined as the composite endpoint of death, or requirement for vasopressors, invasive mechanical ventilation and/or renal replacement therapy.

Results: 189 patients were included, 98 in 2004-2012 and 91 in 2013-2017, most often from West and Central African countries (96\%). The number of WHO criteria for severe malaria was comparable in both groups, but SAPS II, SOFA and ICU length of stay were significantly higher in 2004-2012, while patients of African origin living in France were less frequent $(p<0.01)$. The outcome was poor for $41 / 98$ cases in 2004-2012 and 12/91 cases in 2013-2017 $(p<0.01)$. The risk factors of poor outcome on the multivariate logistic regression were a neurological failure (adjusted odds ratio (adjOR $=3.23 ; 95 \% \mathrm{Cl}(1.03-10.08), p=0.004)$, cardio-circulatory failure (adjOR $=9.92 ; 95 \% \mathrm{Cl}(2.34-42), p=<0.01)$ and creatinine blood levels $>265 \mu \mathrm{mol} / \mathrm{L}$ (adjOR $=10.76 ; 95 \% \mathrm{Cl}(3.17-36.53), p<0.01)$. In the multivariate analysis, IV artesunate was not associated with a better outcome. Patients of African origin did not seem to have a better outcome than Caucasian patients or those from other origins (adjOR $=0.59 ; 95 \% \mathrm{Cl}(0.21-1.65), p=0.31$ ).
\end{abstract}

Conclusion: Patients with imported malaria admitted in ICU in 2013-2017 were less severely ill than those in 2004-2012. These trends could be partially explained by the increasing proportion of African patients visiting friends or relatives or living in endemic areas.

*Correspondence: Jean-francois.timsit@aphp.fr

${ }^{1}$ AP-HP, Bichat Hospital, Medical and Infectious Diseases ICU (MI2), University of Paris, IAME, INSERM U1137 (IAME), 75018 Paris, France

Full list of author information is available at the end of the article the original author(s) and the source, provide a link to the Creative Commons licence, and indicate if changes were made. The images or other third party material in this article are included in the article's Creative Commons licence, unless indicated otherwise in a credit line to the material. If material is not included in the article's Creative Commons licence and your intended use is not permitted by statutory regulation or exceeds the permitted use, you will need to obtain permission directly from the copyright holder. To view a copy of this licence, visit http://creativecommons.org/licenses/by/4.0/. 
Keywords: Severe malaria, Critically ill, Sepsis, Outcome, Artesunate

\section{Background}

Half of the world's population is still exposed to malaria, causing an estimated 228 million of clinical cases associated to 405,000 deaths in 2018. The African continent is the most impacted by Plasmodium infection, with still $93 \%$ of all worldwide clinical malaria cases and $94 \%$ of worldwide deaths, mostly in young children. However, although the malaria incidence rate decreased by $21 \%$ between 2010 and 2015, thanks to successive health policies aiming to decrease Plasmodium spp. exposition in local populations of endemic countries, it remains stable since 2015 [1].

France is the non-endemic European countries most affected by malaria imported cases, increasing since 2012 [2-4], from 3580 estimated infected patients in 2012 to 5550 in 2018 (+55\%). The associated mortality rate reached $0.39 \%$. The increased incidence is likely explained by the growing number of African people visiting friends and relatives (VFR) in sub-Saharan countries and coming back to Western European countries such as France [5].

Importantly, during the last decade, the guidelines for the diagnosis and management of severe malaria cases have undergone major changes in endemic area and in France. Available in compassionate use in France since May 2011, artesunate became the first-line treatment for severe malaria. This drug is associated with a reduced mortality in endemic areas [6,7], was shown to improve survival versus quinine in South-East Asia and Africa, to reduce parasite clearance time, and to shorten the ICU and hospital lengths of stay in non-endemic countries [8]. Its effectiveness and tolerance made it a good choice to replace intravenous quinine in European countries.

During the past decade, the characteristics of severe imported malaria cases referred to our intensive care unit (ICU) changed markedly. Patients were less often Caucasian tourists, presented less often with multiple organ failures, and seemed to recover more quickly. Therefore, we decided to further assess these epidemiologic changes and the potential impact of the widespread increase in the use of artesunate as a first-choice therapy on the improvement of prognosis.

The aim of this single-center study was to assess the evolution of the epidemiology, clinical presentation and outcome in severe imported malaria patients in an ICU of a referral hospital during the last 14 years. Our first objective was to assess over the years the clinical presentation, treatment and outcome in patients with severe imported malaria. The second one was to evaluate whether the changes in the outcome were correlated with the epidemiological evolution of patients with severe imported malaria, or with the availability of IV artesunate.

\section{Methods \\ Study population}

The study was performed in the infectious diseases ICU of Bichat-Claude Bernard University hospital in Paris. Every patient admitted with a diagnosis of severe malaria between January 2004 and December 2017 was included. Hospitalization report database and biological data were retrospectively collected.

According to the French recommendations for the management of severe imported malaria, adapted from the 2014 WHO's definition [9], severe imported malaria cases were defined by the presence of Plasmodium falciparum parasites in peripheral blood (or, more rarely, of one of the four other Plasmodium species), associated with one or more defined severe clinical conditions or biological findings. Clinical criteria included neurological failure (with obnubilation, confusion or prostration, Glasgow Coma Scale $<11$, or multiple seizures), respiratory failure (requirement for mechanical ventilation with $\mathrm{PaO}_{2} / \mathrm{FiO}_{2}<300 \mathrm{mmHg}$ or spontaneous breathing with $\mathrm{PaO}_{2}<60 \mathrm{mmHg}$ and/or respiratory rate $>30$ per min), cardio-circulatory failure (systolic blood pressure $<80 \mathrm{mmHg}$ despite adequate volume repletion or need for vasoactive drugs), hemorrhage, or jaundice. Laboratory criteria included hyperlactatemia (serum lactate $>2 \mathrm{mmol} / \mathrm{L})$, acidosis $(\mathrm{pH}<7.35)$, renal impairment (serum creatinine $>265 \mu \mathrm{mol} / \mathrm{L}$ ), hyperparasitemia ( $>4 \%$ ), hypoglycemia (blood glucose $<2.2 \mathrm{mmol} / \mathrm{L}$ ) and severe anemia (hemoglobin $<7 \mathrm{~g} / \mathrm{dL}$ ). Severity criteria were collected within the first hour of ICU admission.

\section{Data collection}

Patients' characteristics and outcomes were compared across two periods, namely from 2004 to end 2012 (1st study period) and from 2013 to 2017 (2nd study period), i.e., before and after artesunate became the first-choice treatment.

The demographic variables such as age, sex, ethnicity (Caucasian, African living in France or in Africa), visited endemic area, length of stay in endemic areas, chemoprophylaxis strategy applied, cause of travel, time between symptoms onset and ICU admission, previous therapy before ICU admission, medical history of prior malaria infection clinical and biological 
parameters during the first hour following ICU admission, curative treatment used, and ICU and hospital lengths of stay were collected. Malaria serology was also performed for all patients whom diagnosis was confirmed in our laboratory. As the exact time of the anti-malarial therapy start before ICU admission was not always available, it was recorded as a Likert scale variable (never, $<8 \mathrm{~h},<24 \mathrm{~h}, \geq 24 \mathrm{~h}$ ). The illness severity at ICU admission was assessed using the Simplified Acute Physiology Score II (SAPS II) and Sepsis-related Organ Failure Assessment (SOFA) score. A postartesunate delayed hemolysis was sought in follow-up consultations and defined as a decrease in hemoglobin associated with haptoglobin $<0.1 \mathrm{~g} / \mathrm{L}$ or $\mathrm{LDH}>390$ IL/L more than 7 days after treatment initiation with artesunate.

\section{Outcomes}

We defined a poor outcome as a composite endpoint comprising death, or requirement for vasopressors, invasive mechanical ventilation (MV) and/or renal replacement therapy (RRT).

\section{Indirect immunofluorescence assay (IIFA)}

The detection and the quantification of total antibodies against Plasmodium falciparum were used to identify a previous exposure to Plasmodium spp. Anti-plasmodial IgG/A/M antibodies were detected and quantified by serological screening based on indirect immunofluorescence assay (IIFA) using whole schizonts of the 3D7 $P$. falciparum strain as crude antigens, and fluoresceinlinked anti-human IgG/A/M (Biorad ${ }^{\circledR}$; Hercules, California, USA) as conjugate. Quantification of plasmatic antibody concentration was estimated by serologic titers. For statistical analysis, antibody titers were classified into three groups: negative if $<1: 64$; positive for titers from 1:64 to 1:1024 and highly positive for titers $>1: 1024$.

\section{Statistical analysis}

Univariate analysis (Mann-Whitney or Chi-square tests as appropriate) was performed to unveil differences between both study periods. A similar analysis was used to select variables associated with poor outcome. Quantitative clinical and biological variables were transformed into dummy variables according to WHO criteria for severity. Variables with a $p$ value of 0.1 or less were proposed for selection in a logistic regression model with stepwise selection stratified by period. Data are presented as median (interquartile range) or numbers (\%). We used the SAS 9.4 software for all statistical analyses.

\section{Results}

\section{Patient characteristics}

From 2004 to 2017, 189 patients were admitted to our ICU for severe imported malaria. Demographic data are shown in Table 1. The median age was 45.3 years and 63\% of the patients were male. The infection was most often acquired in West and Central Africa (96\%). Most patients travelled to visit friends or relatives (52\%) and took a partial anti-malarial chemoprophylaxis (94\%). Thirty-seven patients (19\%) were living in endemic countries and were travelling in France. The proportion of European people travelling for tourism or work was below one-third and seemed to be decreasing over the years (Fig. 1). Among travellers, the median duration of stay in endemic area was 30 days. The median duration of symptoms before ICU admission was 6 days.

Plasmodium falciparum was identified in 184 cases out of the 189 patients (97\%). The other species responsible for severe malaria were Plasmodium vivax (three patients), Plasmodium ovale (one patient) and Plasmodium malariae (one patient). These latter patients experienced more specifically circulatory failure (four patients) and respiratory distress syndrome (one patient).

The median parasitemia was 5.3\% [1.5;9] and hyperparasitemia above $4 \%$ was the most commonly observed criteria of severe malaria (59\%), as well as hyperlactatemia above $2 \mathrm{mmol} / \mathrm{L}$ (41\%), jaundice or bilirubin blood levels above $50 \mu \mathrm{mol} / \mathrm{L}$ (39\%). Although neurological failures were often observed (36\%), only one out of ten patients presented a Glasgow Coma score below 11 or multiples seizures.

Underlying chronic conditions were reported in $31 \%$ of patients (58/189), most often hypertension and diabetes mellitus. The HIV status was known positive in $10 \%$ (18/189), two of them were at AIDS stage. Two patients were 4 months pregnant.

\section{First and second study periods}

The proportion of people living in endemic areas or travelling for VFR increased from $66 \%$ in the first period to $78 \%$ in the second period $(p=0.07)$. During the second period, the number of severe imported malaria cases in Caucasian people decreased, while that in African people living in France increased significantly $(p<0.01)$. A medical history of prior malaria was less frequently observed during the first period than after, with, respectively, 16 $(16 \%)$ and $28(31 \%)$ patients $(p=0.02)$, although the proportions of positive malaria serology were comparable between periods. The lack of observance of anti-malarial chemoprophylaxis was deemed similar across periods, with still less than one patient out of ten taking a complete chemoprophylaxis. The platelet count was not 
Table 1 Characteristics of patients with severe imported malaria

\begin{tabular}{|c|c|c|c|c|}
\hline Characteristics & Total & 2004-2012 & 2013-2017 & $\mathrm{p}$ value \\
\hline Number of patients & $189^{*}$ & 98 & 91 & \\
\hline Gender, male & $119(63)$ & $65(66)$ & $54(59)$ & 0.32 \\
\hline Age, median in years [IQR] & $45[31 ; 56]$ & $45[29 ; 56]$ & $45[33 ; 57]$ & 0.33 \\
\hline Clinical history of previous malaria & $44(23)$ & $16(16)$ & $28(31)$ & 0.02 \\
\hline Positive malaria serology & $89(47)$ & $45(66)$ & $44(63)$ & 0.68 \\
\hline Highly positive (IIFA > 1:1024) & $29(15)$ & $17(17)$ & $12(13)$ & 0.36 \\
\hline Positive (IIFA from 1:64 to 1:1024) & $60(32)$ & $28(29)$ & $32(35)$ & \\
\hline Negative (IIFA < 1:64) & $49(26)$ & $23(23)$ & $26(29)$ & . \\
\hline Missing & $51(27)$ & $30(31)$ & $21(23)$ & . \\
\hline Ethnic group & & & & $<.01$ \\
\hline Caucasian & $51(27)$ & $36(37)$ & $15(16)$ & \\
\hline African & $138(73)$ & $62(63)$ & $76(84)$ & \\
\hline African living in France & $121(64)$ & $53(54)$ & $68(75)$ & . \\
\hline African living in Africa & $17(9)$ & $9(9)$ & $8(9)$ & . \\
\hline Cause of travel & & & & 0.07 \\
\hline Visiting friends and relatives/living in endemic areas & $136(72)$ & $65(66)$ & $71(78)$ & \\
\hline Europeans travelling for tourism or work & $53(28)$ & $33(34)$ & $20(22)$ & . \\
\hline Complete anti-malarial chemoprophylaxis & $12(6)$ & $6(6)$ & $6(7)$ & 0.89 \\
\hline Travel in West and Central Africa & $182(96)$ & $92(94)$ & $90(99)$ & 0.07 \\
\hline Plasmodium falciparum & $184(97)$ & $95(97)$ & $89(98)$ & 0.71 \\
\hline $\begin{array}{l}\text { Time from symptoms onset to ICU admission, median in days } \\
\text { [IQR] }\end{array}$ & $6[4,9]$ & $6[4,9]$ & $5[3,9]$ & 0.08 \\
\hline Treatment started at the time of ICU admission & $91(48.9)$ & $47(49.5)$ & $44(48.4)$ & 0.43 \\
\hline Treatment started $<8 \mathrm{~h}$ before ICU admission & $59(31.7)$ & $27(28.4)$ & $32(35.2)$ & \\
\hline Treatment started $<24 \mathrm{~h}$ before ICU admission & $11(5.9)$ & $8(8.4)$ & $3(3.3)$ & \\
\hline Treatment started $>24 \mathrm{~h}$ before ICU admission & $25(13.4)$ & $13(13.7)$ & $12(13.2)$ & \\
\hline ICU length of stay, median [IQR] & $2[2,4]$ & $4[2,7]$ & $2[2,3]$ & $<.01$ \\
\hline Hospital length of stay, median [IQR] & $7[5,13]$ & $8[6,15]$ & $7[5,10]$ & 0.05 \\
\hline SAPS II, median [IQR] & $25[18 ; 36]$ & $28[20 ; 36]$ & $22[16 ; 35]$ & 0.03 \\
\hline SOFA, median [IQR] & $6[4,8]$ & $6[5,8]$ & $5[4,7]$ & $<.01$ \\
\hline Mortality & $7(4)$ & $5(5)$ & $2(2)$ & 0.29 \\
\hline
\end{tabular}

ICU: intensive care unit; IQR: interquartile range; IIFA: indirect immunofluorescence assay; SAPS: Simplified Acute Physiology Score; SOFA: Sequential Organ Failure Assessment

* Except for malaria serology there was no missing data of the independent variables

different between periods (2004-2013: 44 G/L [26; 63.5]; 2013-2017: 51 G/L [30; 84]; $p=0.08)$.

Except for renal insufficiency (30\% before 2013, 18\% after 2013, $p=0.05$ ), the illness severity criteria were comparable between both periods (Table 2), including the median parasitemia. Even if the number of WHO criteria for severe malaria on admission was similar between both groups (median $=2, p=0.28$ ), the ICU severity scores were significantly lower during the second period: the median SAPS II decreased from 28 to $22(p=0.03)$ and the median SOFA score from 6 to $5(p<0.01)$. During the second period, the median ICU length of stay was shorter by 2 days $(p<0.01)$ and the median hospital length of stay by 1 day $(p=0.05)$.

The proportion of patients treated with artesunate was $12.2 \%$ (12/98 patients) during the first period as artesunate became progressively available in France since May 2011. After 2012, it reached 92.3\% (84/91 patients) while the other seven patients received intravenous quinine, including four cases treated in another hospital before ICU admission, the two pregnant women and the case of Plasmodium malariae. The anti-malarial treatment was started before ICU admission in one patient out of two, without any significant difference between both periods $(p=0.43)$. 


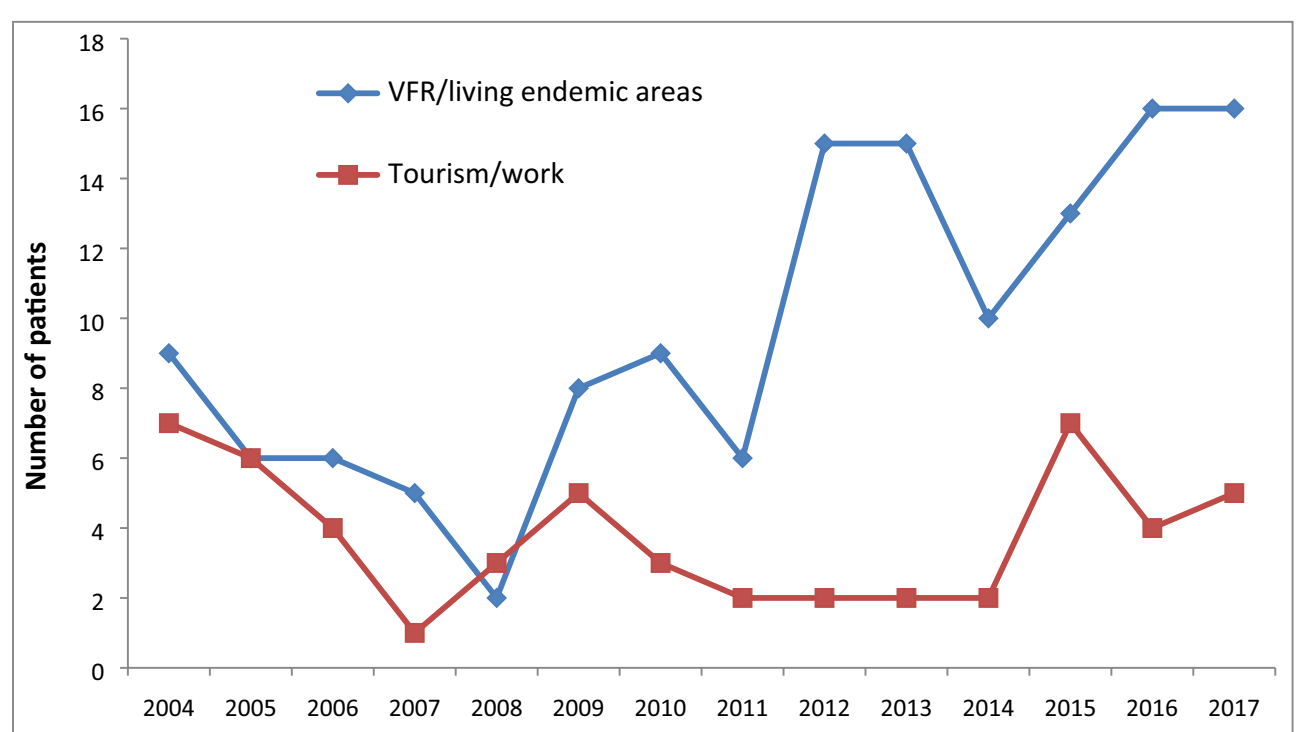

Fig. 1 Evolution of the number of severe imported malaria cases according to the reasons for stay in endemic areas. VFR: visiting friends and relatives

Table 2 Criteria leading to classification as severe malaria on admission

\begin{tabular}{|c|c|c|c|c|}
\hline Severe malaria criteria & Total & 2004-2012 & 2013-2017 & $p$ value \\
\hline $\begin{array}{l}\text { Neurological failure: obnubilation, confusion, GCS }<11 \text { or } \\
\text { multiple seizures }\end{array}$ & $68(36)$ & $35(36)$ & $33(36)$ & 0.94 \\
\hline Glasgow Coma Scale $<11$ & $17(9)$ & $12(12)$ & $5(5)$ & 0.13 \\
\hline Multiples seizures & $8(4)$ & $6(6)$ & $2(2)$ & 0.18 \\
\hline Respiratory failure & $11(6)$ & $5(5)$ & $6(7)$ & 0.66 \\
\hline Cardio-circulatory failure & $36(19)$ & $16(16)$ & $20(22)$ & 0.31 \\
\hline Hemorrhage & $3(2)$ & $2(2)$ & $1(1)$ & 0.6 \\
\hline Clinical jaundice or bilirubin $>50 \mu \mathrm{mol} / \mathrm{L}$ & $73(39)$ & $42(43)$ & $31(34)$ & 0.21 \\
\hline Hyperlactatemia $>2$ mmol/L & $77(41)$ & $42(43)$ & $35(38)$ & 0.54 \\
\hline Lactate, median [IQR] & $2.1[1.2 ; 3.2]$ & $2.1[1.2 ; 3.5]$ & $1.8[1.2 ; 2.8]$ & 0.32 \\
\hline Acidosis: $\mathrm{pH}<7.35$ & $21(11)$ & $14(14)$ & $7(8)$ & 0.15 \\
\hline pH, median [IQR] & $7.4[7.4 ; 7.5]$ & $7.4[7.4 ; 7.5]$ & $7.4[7.4 ; 7.5]$ & 0.2 \\
\hline Renal impairment: serum creatinine $>265 \mu \mathrm{mol} / \mathrm{L}$ & $45(24)$ & $29(30)$ & $16(18)$ & 0.05 \\
\hline Creatinine, median [IQR] & $120[82 ; 247]$ & $140[92 ; 280]$ & $107[77 ; 197]$ & $<.01$ \\
\hline Hyperparasitemia $>4 \%$ & $112(59)$ & $59(60)$ & $53(58)$ & 0.78 \\
\hline Parasitemia, median in \% [IQR] & $5.3[1.5 ; 9]$ & $5.3[2,10]$ & $5.3[1.2 ; 7.7]$ & 0.3 \\
\hline Hypoglycemia: blood glucose $<2.2 \mathrm{mmol} / \mathrm{L}$ & $1(0.5))$ & $1(1)$ & $0(0)$ & - \\
\hline Severe anemia: hemoglobin $<7 \mathrm{~g} / \mathrm{dL}$ & $22(12)$ & $15(15)$ & $7(8)$ & 0.1 \\
\hline Number of severe criteria, median [IQR] & $2[1,4]$ & $2[1,4]$ & $2[1,3]$ & 0.28 \\
\hline
\end{tabular}

GCS: Glasgow Coma Scale; IQR: interquartile range

\section{Outcome}

A poor outcome, comprising death, requirement for vasopressors, invasive mechanical ventilation and/or renal replacement therapy, occurred in 41 (42\%) and 12 (13\%) patients during each period, respectively $(p<0.01)$ (Table 3$)$. Patients' characteristics and severity criteria at ICU admission, according to outcome are shown in Table 4. The evolution of the number of poor and good outcomes over time is shown in Fig. 2.

Seven patients died during hospital stay (3.7\%). Five of them died within the first week of care, and the two latter after a prolonged hospitalization stay and because of 
Table 3 Outcome of patients with severe malaria

\begin{tabular}{|c|c|c|c|c|}
\hline Outcome & All patients & 2004-2012 & 2013-2017 & $p$ value \\
\hline Death & $7(4)$ & $5(5)$ & $2(2)$ & 0.29 \\
\hline Need of vasopressors & $19(10)$ & $13(13)$ & $6(7)$ & 0.13 \\
\hline Need of mechanical ventilation & $34(18)$ & $28(29)$ & $6(7)$ & $<.01$ \\
\hline Need of renal replacement therapy & $35(19)$ & $26(27)$ & $9(10)$ & $<.01$ \\
\hline Poor outcome & $53(28)$ & $41(42)$ & $12(13)$ & $<.01$ \\
\hline
\end{tabular}

Table 4 Patients' characteristics and severity criteria at ICU admission, according to outcome

\begin{tabular}{|c|c|c|c|c|c|}
\hline Patients characteristics & Good outcome & Poor outcome & OR & $95 \% \mathrm{Cl}$ & $p$ value \\
\hline Number of patients & 136 & 53 & & & \\
\hline Gender, male & $85(62)$ & $34(64)$ & 0.96 & {$[0.48 ; 1.92]$} & 0.91 \\
\hline Age, median [IQR] & $45[31 ; 57]$ & $48[31 ; 54]$ & 1.01 & {$[0.98 ; 1.02]$} & 0.83 \\
\hline Clinical history of prior malaria & $39(29)$ & $5(9)$ & 0.32 & {$[0.11 ; 0.88]$} & 0.03 \\
\hline Positive malaria serology & $68(64)$ & $21(66)$ & 1.02 & {$[0.44 ; 2.38]$} & 0.96 \\
\hline \multicolumn{6}{|l|}{ Ethnic group } \\
\hline Caucasian & $27(20)$ & $24(45)$ & 1 & & 0.03 \\
\hline African & $109(80)$ & $29(54)$ & 0.3 & {$[0.15 ; 0.6]$} & $<.01$ \\
\hline African living in France & $97(71)$ & $24(45)$ & 0.37 & {$[0.17 ; 0.76]$} & $<.01$ \\
\hline African living in Africa & $12(9)$ & $5(9)$ & 0.56 & {$[0.16 ; 1.92]$} & 0.36 \\
\hline \multicolumn{6}{|l|}{ Cause of travel } \\
\hline Visiting friends and relatives/living in endemic areas & $106(78)$ & $30(57)$ & 0.42 & {$[0.2 ; 0.85]$} & 0.02 \\
\hline Europeans travelling for tourism or work & $30(22)$ & $23(43)$ & 1 & & \\
\hline Complete chemoprophylaxis & $11(8)$ & $1(2)$ & 0.2 & {$[0.02 ; 1.67]$} & 0.14 \\
\hline $\begin{array}{l}\text { Time from symptoms onset to ICU admission, median in } \\
\text { days [IQR] }\end{array}$ & $5[4,8]$ & $7[4,9]$ & 1.04 & {$[1.01 ; 1.19]$} & 0.02 \\
\hline Treatment started before ICU admission & $67(49)$ & $31(58)$ & 1.49 & {$[0.76 ; 2.94]$} & 0.24 \\
\hline \multicolumn{6}{|l|}{ Treatment administered } \\
\hline Artesunate & $81(60)$ & $15(28)$ & 0.72 & {$[0.25 ; 2.1]$} & 0.55 \\
\hline Intravenous quinine & $55(40)$ & $38(72)$ & 1 & & \\
\hline SAPS II, median [IQR] & $21[16,30]$ & $41[31 ; 56]$ & 1.14 & {$[1.09 ; 1.19]$} & $<.01$ \\
\hline SOFA, median [IQR] & $5[3,6]$ & $8[7,12]$ & 1.92 & {$[1.55 ; 2.37]$} & $<.01$ \\
\hline Parasitemia median in \% [IQR] & $5.1[1.6 ; 8.0]$ & $5.9[1.5 ; 13.6]$ & 1.03 & {$[0.99 ; 1.07]$} & 0.16 \\
\hline Severity criteria & Good outcome & Poor outcome & OR & $95 \% \mathrm{Cl}$ & $p$ value \\
\hline Neurological failure & $38(28)$ & $30(57)$ & 3.98 & {$[1.94 ; 8.15]$} & $<.01$ \\
\hline Respiratory failure & $2(1)$ & $9(17)$ & 23.61 & {$[4.38 ; 127]$} & $<.01$ \\
\hline Cardio-circulatory failure & $17(12)$ & $19(36)$ & 10.62 & {$[3.67 ; 30.68]$} & $<.01$ \\
\hline Bilirubin $>50 \mu \mathrm{mol} / \mathrm{L}$ & $49(36)$ & $24(45)$ & 1.32 & {$[0.67 ; 2.6]$} & 0.42 \\
\hline Serum creatinine $>265 \mu \mathrm{mol} / \mathrm{L}$ & $16(12)$ & $29(55)$ & 8.86 & {$[3.98 ; 19.71]$} & $<.01$ \\
\hline Severe anemia: hemoglobin $<7 \mathrm{~g} / \mathrm{dL}$ & $15(11)$ & $7(13)$ & 0.95 & {$[0.35 ; 2.59]$} & 0.92 \\
\hline Acidosis: $\mathrm{pH}<7.35$ & $5(4)$ & $16(30)$ & 11.53 & {$[3.71 ; 35.83]$} & $<.01$ \\
\hline Hyperlactatemia $>2$ mmol/L & $46(34)$ & $31(59)$ & 2.86 & {$[1.44 ; 5.69]$} & $<.01$ \\
\hline Hyperparasitemia $>4 \%$ & $78(57)$ & $34(64)$ & 1.33 & {$[0.67 ; 2.64]$} & 0.42 \\
\hline Number of severity criteria, median [IQR] & $2[1,3]$ & $4[2,5]$ & 2.16 & {$[1.66 ; 2.81]$} & $<.01$ \\
\hline
\end{tabular}




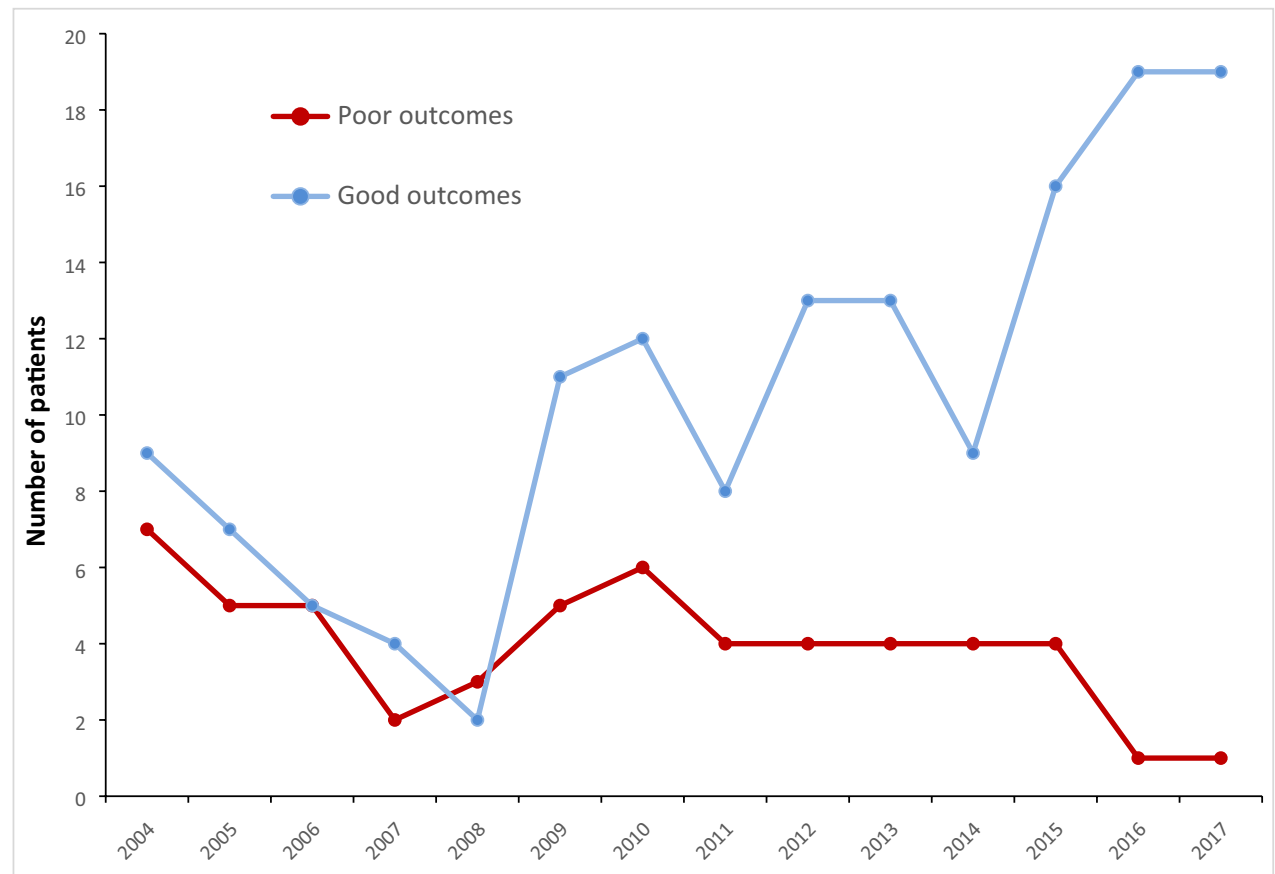

Fig. 2 Evolution of the number of poor outcomes and good outcomes of severe imported malaria cases

severe comorbidities. Four of these seven patients were transferred from another hospital and three of them did not receive any anti-malarial treatment before admission in our ICU. During their ICU stay, 19 patients (10\%) needed vasopressors. An invasive mechanical ventilation was initiated in 35 (19\%) patients, for 5 days in median. Twenty-three patients were intubated because of neurologic impairment, ten for respiratory distress, one for hemorrhagic shock and one for cardiac arrest. Thirtysix patients $(19 \%)$ needed a renal replacement therapy throughout their full stay in ICU, for 4 days in median. Only two patients still needed hemodialysis after 1 month of care; however, their renal function recovered after 3 and 6 months, respectively. Erythrocytes transfusions were reported in 17 patients (9\%) during ICU stay. Two patients suffered from splenic rupture. A postartesunate delayed hemolysis was reported in follow-up consultations with ID physicians for 8/84 (9.5\%) patients of the 2nd period. Symptomatic hypoglycemia occurred in three ICU patients, all treated with intravenous quinine. Only one patient presented severe hypoglycemia on admission before quinine administration.

In univariate analysis, the risk factors of poor outcome were neurological failure, respiratory failure, circulatory collapse, and creatinine serum level above $265 \mu \mathrm{mol} / \mathrm{L}$.

In multivariate analysis, the risk factors of poor outcome were neurological failure, circulatory collapse and creatinine serum level above $265 \mu \mathrm{mol} / \mathrm{L}$ (Table 5).
African-origin patients did not seem to have a better outcome than Caucasian or other origin patients $(\operatorname{adjOR}=0.59 ; 95 \%$ CI $(0.21-1.65), p=0.31)$. When forced in the final prognostic model, artesunate-based therapy did not appear to be different from quininebased therapy in term of prognosis $(\operatorname{adjOR}=0.29 ; 95 \% \mathrm{CI}$ (0.04-2.03), $p=0.21$ ).

\section{Discussion}

The major finding of our study conducted in a referral ICU for severe imported malaria in the Parisian area is that, despite no clear modification of the number and types of WHO criteria of patients throughout both study periods, the patients had a less severe disease as estimated by the SAPS II and a better prognosis during the 2013-2017 time period. These changes in presentation and prognosis were not related to an earlier initiation of therapy and not clearly related to the widespread use of artesunate, but were associated with changes in the population over time. Patients were hospitalized with a significantly lower SAPS II scores, but without significant modifications of the number of severity criteria at ICU admission.

Among 189 patients admitted in this ICU, the in-hospital mortality was $3.7 \%$, lower than that described in previous studies among patients admitted for severe imported malaria [10-12]. In the multicentric SIMA study [10], 35 patients (including two deaths) of our ICU were included 
Table 5 Independent predictors of poor outcome at ICU admission, multivariate analysis

\begin{tabular}{|c|c|c|c|c|c|}
\hline Patients characteristics & Estimate & Std error & adjOR & $95 \% \mathrm{Cl}$ & $p$ value \\
\hline Ethnic group & & & & & 0.31 \\
\hline Caucasian and others & Ref & & 1 & & \\
\hline African & -0.53 & 0.53 & 0.59 & {$[0.21 ; 1.65]$} & \\
\hline Treatment administered & & & & & 0.21 \\
\hline Artesunate & Ref & & 1 & & \\
\hline Intravenous quinine & 1.23 & 0.99 & 3.43 & {$[0.49 ; 23.9]$} & \\
\hline \multicolumn{6}{|l|}{ Severity criteria on admission } \\
\hline Neurological failure & 1.17 & 0.58 & 3.23 & {$[1.03 ; 10.08]$} & 0.04 \\
\hline Cardio-circulatory failure & 2.3 & 0.74 & 9.92 & {$[2.34 ; 42]$} & $<.01$ \\
\hline Serum creatinine $>265 \mu \mathrm{mol} / \mathrm{L}$ & 2.38 & 0.62 & 10.76 & {$[3.17 ; 36.56]$} & $<.01$ \\
\hline
\end{tabular}

Std error: standard error; adjOR: adjusted odds ratio; $95 \% \mathrm{Cl}$ : 95\% confidence interval

NB: variables entered in the stepwise logistic regression model at the first step were: ethnic group; parasitemia greater than $4 \%$, neurological failure; shock; lactate level greater than 1_8 mmol/L; $\mathrm{pH}<7.35$; serum creatinine $>265 \mu \mathrm{mol} / \mathrm{L}$; bilirubin level $>50 \mathrm{IU}$; clinical history of prior malaria; cause of travel

with a lower mortality rate than in other centers $(5.7 \%$ vs 10.9\%). These results might be explained by the expertise of our ICU in the management of severe imported malaria. Recently, the French Artesunate Working Group analyzed the cohort of all severe imported malaria patients reported from 2011 to 2017, treated with artesunate or quinine, and observed a death rate of $3.2 \%$, comparable to our result [13].

As the mortality associated with severe imported malaria is low, we defined a poor outcome as the composite endpoint of death, need of vasopressors, mechanical ventilation and/or renal replacement therapy. The association between severity criteria of malaria such as serum creatinine level above $265 \mu \mathrm{mol} / \mathrm{L}$ or cardiocirculatory, respiratory or neurological failures and our poor outcome seems obvious, but these criteria are universal predictors of poor prognosis on ICU admission. Acidosis and hyperlactatemia were also associated with a poorer prognosis. Other severity criteria of malaria, such as hyperparasitemia above $4 \%$, did not seem associated with a poorer prognosis. Importantly, patients of African origin living in France, patients with prior exposure to malaria and with a shorter time from onset symptoms to ICU admission, had a better prognosis.

One of the explanations for the rise of severe imported malaria cases for the French national reference center was a significant and regular decrease in the proportion of people taking complete chemoprophylaxis [2]. We did not observe such a drop in our population over time, as our rate of patients who took complete anti-malarial chemoprophylaxis remained steadily very low. This shows that an important work on the education of these patients is still needed.

On the other hand, the French Reference Center explained the decreasing mortality rate in the recent years by the preponderant part of African-origin patients in severe imported malaria cases having a self-reported previous history of malaria [2]. A prior exposure to Plasmodium falciparum seems to induce a protection against severe malaria by generating antibody levels which are able to significantly reduce the circulating and sequestered parasite burden [13]. A persistence of some kind of protection after leaving malaria endemic areas is suspected, but the number of years covered by that protection is not well defined and needs further studies. In our work, we also observed a better outcome for patients with prior exposure, but we did not identify any correlation between a positive malaria serology and a good outcome. Data were missing for 51 patients (27\%), mostly because those patients were transferred from another hospital. This finding questioned the need to develop better immunological tools to identify pre-exposed patients. While the number of travellers remained stable over the years, the proportion of patients living in endemic areas or VFR increased since 2008 (Fig. 1). Numerous associations between genetic polymorphisms and prognosis of severe malaria have been advocated [14-20], but formal confirmations using large multicenter worldwide cohorts are lacking. Independently of definite pathophysiological explanation, the changes in population may be one of the reasons for the better outcome of patients with severe imported malaria during the second period.

We observed several cases of African patients living in Africa hospitalized for severe imported malaria in our hospital. This population of African people travelling in France to visit friends and relatives was limited, but it exemplified that African adults may present severe malaria which needs ICU management in European countries. The worldwide decreased exposure to Plasmodium species with the rise of preventive measures 
induced a decreased incidence of malaria cases [21]. Perraut et al. found that immunity with antigen-specific antibody declined in the youngest population in endemic areas. The consequence of this waning immunity might be an increased incidence of cases of severe imported malaria in the future [22].

The development of new diagnostic tools as well as new recommendations for malaria management such as the introduction of artesunate as the first-line of treatment for severe imported malaria since 2013 could also have had an impact on the mortality rate of severe imported malaria. However, no difference were observed in the time interval between symptoms onset to ICU admission across both periods. SIMA and PALUREA, the two largest studies of imported malaria in France [10, 11], were conducted before the availability of artesunate. Their mortality rates were higher than in our study, with death occurring during the first week of hospitalization in three out of four patients. In these two studies, the proportion of patients needing the use of vasopressors, mechanical ventilation or renal replacement therapy is shown in table E1, as well as a review of other studies of severe imported malaria $[8,23,24]$. The risk factors associated with mortality in the SIMA cohort study were an older age, a low Glasgow Coma Scale score and a high parasitemia. In the PALUREA study, three host-related biomarkers were associated with severe malaria, namely a high level of procalcitonin and STREM-1, and a low level of albumin. As parasitemia only reflects the circulating parasites, which are less pathogenic than the sequestered parasites, another parasite-related biomarker, PfHRP2, is usually considered more relevant than parasitemia to identify severe malaria [25]. However, this biomarker does not allow to differentiate severe malaria with organ injuries from a "simple" hyperparasitemic severe malaria case $[13,26]$. All those biomarkers were not systematically collected in our retrospective study and could not be analyzed.

The TropNet severe malaria study showed that a treatment with artesunate reduced the parasite clearance time and was associated with shorter ICU and hospital lengths-of-stay [8]. The initiation of an anti-malarial treatment is an emergency and previous studies demonstrated that a better prognostic was associated with a shorter time between the first symptoms and the initiation of treatment administration [27, 28]. However, we could not demonstrate that patients with better outcome had an earlier initiation of treatment. In our study, even a treatment started before ICU admission was not significantly associated with a better outcome. Nevertheless, we observed that $3 / 7$ deaths occurred in patients transferred from another hospital without any administration of anti-malarial agents. We did not analyze the anti-malarial treatment that may have followed the initial administration of artesunate or quinine, because we estimated that the outcome of severe malaria would depend of the first anti-malarial treatment.

The main limitation of our study is the retrospective and monocentric design in a referral French ICU specialized in infectious diseases. Mortality might have been biased by the fact that our ICU had a long experience in treating severe imported malaria. The absence of difference between artesunate and quinine treatment in this study might be explained by a large experience in IV quinine use and the use of up-to-date standard of ICU care. Adverse effects reported with quinine use were very rare with only three symptomatic episodes of hypoglycemia. The absence of difference may also be due to a lack of study power because of an insufficient number of patients. In 2012, a retrospective study in the United Kingdom compared 24 patients treated with artesunate to 167 patients treated with quinine [29]. The length of stay was shorter in the artesunate group. The authors mentioned that this improvement might have been due either to the artesunate use or to a change in the population admitted. Indeed, they observed a shift in the origins of the patients with a higher proportion of African patients in the artesunate group. We also observed a change in the profile of our patients over time, with a higher proportion of African patients visiting friends or relatives or living in endemic countries.

The French Artesunate Working Group has also yielded the absence of significant impact of artesunate use in France. Indeed, in a country with a high level of care, no difference was found in term of mortality rate or duration of stay of severe malaria treated with artesunate versus quinine [30]. However, artesunate is a safe and effective treatment of severe malaria that became a standard of care, even in high-income countries and our aim was not to question its superiority, but to identify other parameters responsible for the change in prognosis. Post-artesunate delayed hemolysis occurred in $9.5 \%$ of the patients, which seems very low compared to other studies [25]. This event was collected from follow-up consultation reports and may have been underestimated.

In our unit, we did not observe any treatment failure when using artesunate. Treatment failure was defined by the $\mathrm{WHO}$ as the inability to clear malarial parasitemia or prevent recrudescence after treatment. Factors identified by the WHO to contribute to treatment failure were poor patient compliance, drug interactions and resistance [26]. In our study, 96\% of the patients with severe imported malaria were coming back from West and Central Africa and only four patients travelled in Asia where cases of artesunate resistance have been described. The oral treatment following intravenous artesunate was 
artemisin-based combination therapy in most patients. Compliance to the oral treatment was not assessed in our study, as patients were usually already discharged from our ICU at this time.

\section{Conclusion}

In our ICU, the majority of patients admitted with severe imported malaria were of African origin and acquired their infection in West and Central Africa. On admission, those patients were less severe during the period of artesunate use than before. These trends could be partially explained by changes in the exposed population, with an increasing proportion of patients of African origin in the second period.

\section{Supplementary information}

Supplementary information accompanies this paper at https://doi. org/10.1186/s13613-020-0634-4.

Additional file 1. Additional table.

\section{Abbreviations}

adjOR: Adjusted odds ratio; AIDS: Acquired immunodeficiency syndrome; $\mathrm{FiO}_{2}$ : Fraction of inspired oxygen; ICU: Intensive care unit; IIFA: Indirect immunofluorescence assay; IQR: Interquartile range; IV: Intravenous; MV: Mechanical ventilation; OR: Odds ratio; $\mathrm{PaO}_{2}$ : Partial pressure in oxygen; $\mathrm{RRT}$ : Renal replacement therapy; SAPS: Simplified Acute Physiology Score; SOFA: Sequential Organ Failure Assessment; VFR: Visiting friends and relatives; WHO: World Health Organization; 95\% Cl: 95\% confidence interval.

\section{Acknowledgements}

We thank Dr. Celine Feger Emibiotech SA for her technical assistance in editing the manuscript.

\section{Authors' contributions}

Conception and data entry: BM, MW, JFT, JL. Statistical analyses: JFT, SR. Writing: JL, JFT. Careful review of the manuscript and suggested modifications: all. All authors read and approved the final manuscript.

\section{Funding}

None.

\section{Availability of data and materials}

Raw data are available upon request and detail protocol for research only.

\section{Ethics approval and consent to participate}

The ethical committee of Bichat hospital approves the retrospective analyses of data included in the article.

\section{Consent for publication}

All the authors approve the manuscript for publication.

\section{Competing interests}

The authors reported no competing interests related to the manuscript.

\section{Author details}

${ }^{1}$ AP-HP, Bichat Hospital, Medical and Infectious Diseases ICU (MI2), University of Paris, IAME, INSERM U1137 (IAME), 75018 Paris, France. ${ }^{2}$ AP-HP, Bichat Hospital, Mycology Parasitology Department, Malaria National Reference Center, 75018 Paris, France. ${ }^{3}$ University of Paris, IAME, INSERM, 75018 Paris, France. ${ }^{4}$ Longjumeau Hospital, ICU, Longjumeau, France. ${ }^{5}$ UMRS 1136, iPLESP, Institut Pierre-Louis d'épidémiologie et de santé publique, Sorbonne Université, 27,
Rue Chaligny, 75571 Paris 12, France. ${ }^{6}$ OUTCOMEREA Research Network, Drancy, France.

Received: 4 August 2019 Accepted: 30 January 2020

Published online: 12 February 2020

\section{References}

1. WHO. World Health Organization. World malaria report 2019. http://www. who.int/malaria/publications/world-malaria-report-2019. 2019.

2. CNR. Centre de national de référence du Paludisme. Rapport annuel d'activité. Année d'exercice 2016. Paris: CNR; 2017 https://anofel.net/wpcontent/uploads/2019/07/RA_CNR_Paludisme_2016.pdf.

3. ECDC. European Centre for Disease Prevention and Control. Annual epidemiological report for 2016. Stockholm: ECDC; 2017. http://ecdc.europ a.eu/annual-epidemiological-reports/methods.2017. Accessed 10 Dec 2018

4. Thellier M, Simard F, Musset L, Cot M, Velut G, Kendjo E, et al. Changes in malaria epidemiology in France and worldwide, 2000-2015. Med Mal Infect. 2019. https://doi.org/10.1016/j.medmal.2019.06.002 (Epub 2019/07/02)

5. Kendjo E, Houze S, Mouri O, Taieb A, Gay F, Jaureguiberry S, et al. Epidemiologic trends in malaria incidence among travelers returning to metropolitan France, 1996-2016. JAMA Netw Open. 2019;2(4):e191691 (Epub 2019/04/06).

6. Dondorp AM, Desakorn V, Pongtavornpinyo W, Sahassananda D, Silamut K, Chotivanich K, et al. Estimation of the total parasite biomass in acute falciparum malaria from plasma PfHRP2. PLoS Med. 2005;2(8):e204 (Epub 2005/08/18)

7. Dondorp AM, Fanello Cl, Hendriksen IC, Gomes E, Seni A, Chhaganlal KD, et al. Artesunate versus quinine in the treatment of severe falciparum malaria in African children (AQUAMAT): an open-label, randomised trial. Lancet. 2010;376(9753):1647-57 (Epub 2010/11/11).

8. Kurth F, Develoux M, Mechain M, Clerinx J, Antinori S, Gjorup IE, et al. Intravenous artesunate reduces parasite clearance time, duration of intensive care, and hospital treatment in patients with severe malaria in Europe: the TropNet severe malaria study. Clin Infect Dis. 2015;61(9):1441-4 Epub 2015/07/19.

9. SPILF. Management and prevention of imported malaria (Revision 2018 of the 2007 Recommendations for clinical practice). Long text. Med Mal Infect 2018 http://www.infectiologie.com/UserFiles/File/spilf/recos /2017-palu-texte-final-flash.pdf.

10. Bruneel F, Tubach F, Corne P, Megarbane B, Mira JP, Peytel E, et al. Severe imported falciparum malaria: a cohort study in 400 critically ill adults. PLOS ONE. 2010;5(10):e13236 (Epub 2010/10/16).

11. Bruneel F, Tubach F, Mira JP, Houze S, Gibot S, Huisse MG, et al. Imported falciparum malaria in adults: host- and parasite-related factors associated with severity The French prospective multicenter PALUREA cohort study. Intensive Care Med. 2016:42(10):1588-96 (Epub 2016/05/14).

12. Marks ME, Armstrong M, Suvari MM, Batson S, Whitty CJ, Chiodini PL, et al. Severe imported falciparum malaria among adults requiring intensive care: a retrospective study at the hospital for tropical diseases, London. BMC Infect Dis. 2013;13:118 (Epub 2013/03/19)

13. Argy N, Kendjo E, Auge-Courtoi C, Cojean S, Clain J, Houze P, et al. Influence of host factors and parasite biomass on the severity of imported Plasmodium falciparum malaria. PLoS ONE. 2017;12(4):e0175328 (Epub 2017/04/15).

14. Apinjoh TO, Anchang-Kimbi JK, Njua-Yafi C, Ngwai AN, Mugri RN, ClarkTG, et al. Association of candidate gene polymorphisms and TGF-beta/IL-10 levels with malaria in three regions of Cameroon: a case-control study. Malar J. 2014;13:236 (Epub 2014/06/18).

15. Lopera-Mesa TM, Doumbia S, Konate D, Anderson JM, Doumbouya M, Keita AS, et al. Effect of red blood cell variants on childhood malaria in Mali: a prospective cohort study. Lancet Haematol. 2015;2(4):e140-9 (Epub 2015/12/22).

16. Mpimbaza A, Walakira A, Ndeezi G, Katahoire A, Karamagi C, Nsobya SL, et al. Associations between erythrocyte polymorphisms and risks of uncomplicated and severe malaria in Ugandan children: a case control study. PLOS ONE. 2018;13(9):e0203229 (Epub 2018/09/18). 
17. Ndila CM, Uyoga S, Macharia AW, Nyutu G, Peshu N, Ojal J, et al. Human candidate gene polymorphisms and risk of severe malaria in children in Kilifi, Kenya: a case-control association study. Lancet Haematol. 2018;5(8):e333-45 (Epub 2018/07/24).

18. Ravenhall M, Campino S, Sepulveda N, Manjurano A, Nadjm B, Mtove $G$, et al. Novel genetic polymorphisms associated with severe malaria and under selective pressure in North-eastern Tanzania. PLoS Genet. 2018;14(1):e1007172.

19. Scott JA, Berkley JA, Mwangi I, Ochola L, Uyoga S, Macharia A, et al. Relation between falciparum malaria and bacteraemia in Kenyan children: a population-based, case-control study and a longitudinal study. Lancet. 2011;378(9799):1316-23 (Epub 2011/09/10).

20. Uyoga S, Ndila CM, Macharia AW, Nyutu G, Shah S, Peshu N, et al. Glucose-6-phosphate dehydrogenase deficiency and the risk of malaria and other diseases in children in Kenya: a case-control and a cohort study. Lancet Haematol. 2015;2(10):e437-44 (Epub 2015/12/22)

21. Cotter C, Sturrock HJ, Hsiang MS, Liu J, Phillips AA, Hwang J, et al. The changing epidemiology of malaria elimination: new strategies for new challenges. Lancet. 2013;382(9895):900-11 (Epub 2013/04/19).

22. Perraut R, Varela ML, Loucoubar C, Niass O, Sidibe A, Tall A, et al. Serological signatures of declining exposure following intensification of integrated malaria control in two rural Senegalese communities. PLoS ONE. 2017;12(6):e0179146 (Epub 2017/06/14).

23. Antinori S, Corona A, Castelli A, Rech R, Borghi B, Giannotti C, et al. Severe Plasmodium falciparum malaria in the intensive care unit: a 6-year experience in Milano, Italy. Travel Med Infect Dis. 2017;17:43-9 (Epub 2017/05/31)

24. Kreeftmeijer-Vegter AR, van Genderen PJ, Visser LG, Bierman WF, Clerinx J, van Veldhuizen CK, et al. Treatment outcome of intravenous artesunate in patients with severe malaria in the Netherlands and Belgium. Malar J. 2012;11:102 (Epub 2012/04/03).
25. Hendriksen IC, Mwanga-Amumpaire J, von Seidlein L, Mtove G, White LJ, Olaosebikan $\mathrm{R}$, et al. Diagnosing severe falciparum malaria in parasitaemic African children: a prospective evaluation of plasma PfHRP2 measurement. PLoS Med. 2012;9(8):e1001297 (Epub 2012/08/29).

26. Goncalves BP, Fried M, Duffy PE. Parasite burden and severity of malaria in Tanzanian children. N Engl J Med. 2014;371(5):482 (Epub 2014/07/31).

27. Checkley AM, Smith A, Smith V, Blaze M, Bradley D, Chiodini PL, et al. Risk factors for mortality from imported falciparum malaria in the United Kingdom over 20 years: an observational study. BMJ. 2012;344:e2116 (Epub 2012/03/29).

28. Seringe $E$, Thellier M, Fontanet A, Legros F, Bouchaud $O$, Ancelle T, et al. Severe imported Plasmodium falciparum malaria, France, 1996-2003. Emerg Infect Dis. 2011;17(5):807-13 (Epub 2011/05/03).

29. Eder M, Farne H, Cargill T, Abbara A, Davidson RN. Intravenous artesunate versus intravenous quinine in the treatment of severe falciparum malaria: a retrospective evaluation from a UK centre. Pathog Glob Health. 2012;106(3):181-7 (Epub 2012/12/26).

30. Elket N, Kendjo E, Thellier M, Assoumou L, Potard V, Taieb A, et al. Propensity score analysis of artesunate versus quinine for severe imported Plasmodium falciparum malaria in France. Clin Infect Dis. 2020. https://doi. org/10.1093/cid/ciz206.

31. Kurth F, Develoux M, Mechain M, Malvy D, Clerinx J, Antinori S, et al. Severe malaria in Europe: an 8-year multi-centre observational study. Malar J. 2017;16(1):57 (Epub 2017/02/02)

\section{Publisher's Note}

Springer Nature remains neutral with regard to jurisdictional claims in published maps and institutional affiliations.

\section{Submit your manuscript to a SpringerOpen ${ }^{\circ}$ journal and benefit from:}

- Convenient online submission

- Rigorous peer review

- Open access: articles freely available online

- High visibility within the field

- Retaining the copyright to your article

Submit your next manuscript at $\boldsymbol{\nabla}$ springeropen.com 